\title{
REFERENCES
}

Blaschko, H., Cattell, M. \& Kahn, J. L. 1931 J. Physiol. 73, 25.

del Castillo, J., Hoyle, G. \& Machne, X. r953 J. Physiol. 121, 539.

Fatt, P. \& Katz, B. I95 I J. Physiol. 115, 320.

Fatt, P. \& Katz, B. 1953a J. Physiol. 120, 171.

Fatt, P. \& Katz, B. $1953 b$ J. Physiol. 121, 374.

Fatt, P. \& Katz, B. $1953^{c}$ J. Exp. Biol. 30, 433.

Hagiwara, S. 1953 Jap. J. Physiol. 3, 284.

Hill, A. V. 1951 Proc. Roy. Soc. B, 138, 325.

Hoffman, P. 1914 Z. Biol. 63, 411.

Hodgkin, A. L. r95 I Biol. Rev. 26, 339.

Hoyle, G. 1953 J. Exp. Biol. 30, 121.

Hoyle, G. 1954 J. Exp. Biol. 31, 260.

Hoyle, G. 1955 a Proc. Roy. Soc. B, 143, 281.

Hoyle, G. $1955 b$ J. Physiol. 127, 90.

Katz, B. 1949 Biol. Rev. 24, 1.

Kuffler, S. W. \& Vaughan Williams, E. M. 1953 J. Physiol. 121, 289.

Ling, G. \& Gerard, R. W. 1949 J. Cell. Comp. Physiol. 34, 382.

Nagai, T. 1953 Ann. Zool. Jap. 26, 57.

Pringle, J. W. S. 1939 J. Exp. Biol. 16, 220.

Ripley, S. H. \& Ewer, D. W. I951 Nature, Lond., 167, 1066.

Ripley, S. H. \& Ewer, D. W. 1953 S. Afr. J. Sci. 49, 320.

Roeder, K. D. \& Weiant, E. A. I950 J. Exp. Biol. 27, 1.

Schmitt, O. H. \& Dubbert, D. R. 1949 Rev. Sci. Instrum. 20, 170.

Wiersma, C. A. G. 194I Biol. Symp. 3, 259.

Wiersma, C. A. G. I95I J. Exp. Biol. 28, 13.

\section{The scent perception of the honeybee}

\author{
By C. R. Ribbands \\ Bee Department, Rothamsted Experimental Station
}

\author{
(Communicated by V. B. Wigglesworth, F.R.S.-Received 28 May 1954- \\ Revised 26 October 1954)
}

\begin{abstract}
By a new technique it has been shown that honeybees can perceive pure chemical scents in great dilution, and that they can distinguish between mixtures which contain only slightly different proportions of the same two scents.

A honeybee was attracted to the body scent which it left behind some time previously on a glass tube on which it had landed momentarily without exposing its scent organ; this body scent may often aid bees in their foraging activities.

Amputation of seven terminal segments of both antennae greatly impaired the threshold of scent perception.

The scent perception of the honeybee is compared with that of other insects, and the problems which have not yet been solved are emphasized.
\end{abstract}

\section{INTRODUCTION}

The responses of honeybees (Apis mellifera $\mathrm{L}$.) which had been trained to various scented chemicals were studied in detail by Frisch (1919), who concluded that in many respects, including olfactory acuity, the scent perception of honeybees was 
very similar to that of man. The present investigation was commenced because this conclusion is difficult to reconcile with the results of recent experiments which demonstrate the role of the honeybees' own body odour in their recognition of comrades (Kalmus \& Ribbands I952) and enemies (Ribbands I954).

\section{Method}

Liquid scented substances were diluted to known concentrations and placed in specimen tubes in which a standard surface area of each solution was exposed. Ethylene glycol was finally chosen as diluent, because it was apparently odourless, readily miscible with the scents, and sufficiently fluid to be accurately measurable in a pipette.

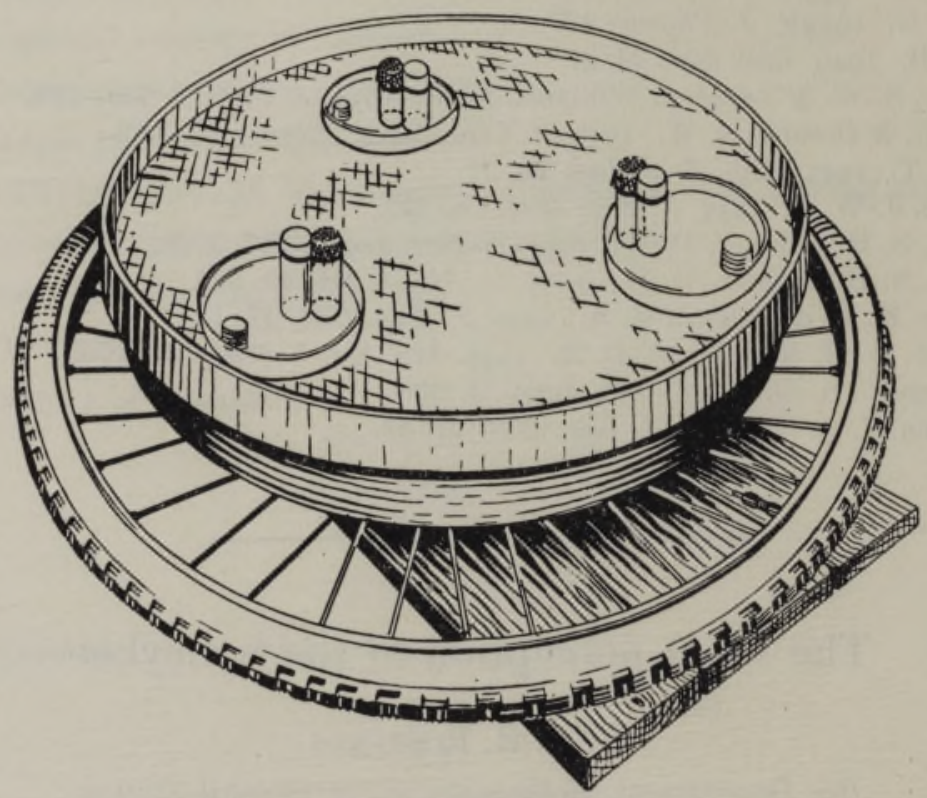

Figure 1. Sketch of the apparatus.

Pairs of $2 \times \frac{3}{4}$ in. glass tubes were fastened together with elastic bands, and each pair was placed on a glass Petri dish. Three such pairs were used at a time, and they were spaced out on a cover (a sieve or a cardboard box) which was placed on a horizontal bicycle wheel (figure 1), which could be slowly rotated.

The training scent was pipetted into one tube, to a depth of $1 \frac{1}{2}$ in., and the top of this tube - called a 'netted tube'-was covered with cotton mosquito netting so that the solution was beyond the reach of bees. The other tube of this pair was filled with sugar solution. One of each of the other pairs of tubes contained ethylene glycol without scent (for threshold experiments) or with another scent (for experiments on discrimination between mixtures of scents), and was netted; the other member of each pair was filled with water. Six to ten individually marked bees* were trained to collect from the tube of sugar solution, and at short intervals

* The foraging bees were not selected in any way; they were probably of various ages and they came from several colonies. 
the bicycle wheel was rotated so that the bees would not become conditioned to forage at any particular position of this table.

After training, sets of new tubes were put out for each test. Three netted tubes were filled with solutions similar to those used during training, but their three partners were empty. During tests the bicycle wheel was slowly rotated; so few bees had been trained that individuals landed one at a time and were not attracted to one another. Bees which landed on top of the pair of tubes with the training scent were counted as positive, and those which landed on either of the other pairs as negative; observations were continued until the number of positives exceeded the number of negatives by five (a significant positive series)* or until the number of negatives exceeded the number of positives by six (which implied absence of discrimination). In the following account landings are recorded as + or - ; for example $(9+4-)$ would refer to a significant positive series in which the bees made four mistakes in landings.

A variable time was required for training. Thoroughly trained bees often would not land on unscented tubes, so (in threshold experiments) positive series were obtained much more quickly than negative ones. To preserve the training each test lasted for only a few minutes, followed by retraining. $1 \%$ solutions were used for training purposes, because it was found that the bees were less certainly and less quickly trained at concentrations near to the threshold of their scent perception.

In threshold experiments the bees were tested on a $1 \%$ solution of the training scent in order to ascertain that they had been trained. Tests with increasingly diluted scent solutions were then made at approximately $30 \mathrm{~min}$ intervals, until a negative series was obtained, followed where possible by a repeat of the positive series at the previous concentration, and then of the negative series at the lowest concentration.

Most of the tests were carried out by my assistants, Mrs Nancy Free and Miss Joan Saunders.

\section{THRESHOLD EXPERIMENTS}

\section{Water perception: non-perception of ethylene glycol}

The above-mentioned technique, modified, was sensitive enough to show that honeybees could be trained to recognize the presence of distilled water which was beyond their reach - an ability demonstrated by Mathilde Hertz (1934). Bees were trained alongside a netted tube with distilled water, and the other two pairs of tubes were empty.

* I am indebted to Mr M. J. R. Healy, Statistics Department, Rothamsted, for this calculation. He states: If no discrimination exists, each of the three pairs of tubes will be visited equally often, so that the proportion of positives in a long series will be approximately one-third; the presence of discrimination will increase this proportion. The method of assessing the results described above has the following properties:

(1) If there is no discrimination, the probability of obtaining a positive series by chance is 0.01 - this is equivalent to the use of a $1 \%$ significance level.

(2) If discrimination exists, the probability of obtaining a negative series depends on the long run proportion of positives. If this proportion is as high as two-thirds, the probability is only 0.05 . 
Tests were made on a windy day (12 August 1952), and a significant positive series $(14+9-)$ was obtained after $3 \mathrm{~h}$ training. The experiment was repeated in a greenhouse (5 November 1952) with the same result $(6+0-)$.

A similar experiment, in which the distilled water was replaced with ethylene glycol, produced an opposite result. Bees trained all day (11 August 1952) produced a negative series $(9+16-)$, and the same result was obtained $(10+21-)$ on the following morning after an additional $1 \frac{1}{2} \mathrm{~h}$ training. This experiment was repeated in a greenhouse (31 October 1952) and a negative series $(1+8-)$ again obtained.

Threshold of scent perception: methyl heptenone in ethylene glycol and liquid paraffin

Bees were trained to $1 \%$ methyl heptenone in ethylene glycol, and on the following morning reacted negatively to $1: 100 \times 10^{6}$ methyl heptenone $(6+11-$ at $10.45 \mathrm{~h}, 1+8-$ at $11.55 \mathrm{~h}$ ), but produced two positive series in respect to $1: 40 \times 10^{6}$ methyl heptenone $(9+2-$ at $11.30 \mathrm{~h}, 8+1-$ at $12.30 \mathrm{~h})$.

Bees were trained to $1 \%$ methyl heptenone in liquid paraffin on 28 October 1952 , in a greenhouse; on the following day there was a significant positive series $(9+4-)$ at $1: 100 \times 10^{6}$, but a negative reaction $(1+6-)$ to the same concentration of methyl heptenone in ethylene glycol. On 30 October $1: 400 \times 10^{6}$ methyl heptenone in liquid paraffin was not recognized $(1+7-)$, but an hour later a positive series $(6+1-)$ was obtained with $1: 100 \times 10^{6}$ methyl heptenone in liquid paraffin.

To reduce the risk of experimental error, the $1: 100 \times 10^{6}$ solutions in both diluents were freshly made up for the experiments on each day; these results suggest that liquid paraffin was a slightly better diluent in respect of threshold values, but that scent perception was of the same order in both diluents.

\section{Threshold of scent perception: various scents in ethylene glycol}

At various times during 1952 bees were trained to $1 \%$ solutions of six different scented chemicals in ethylene glycol. The results are set out in table 1. Three of these scents-phenyl ethyl alcohol, and the open-chain terpenes, geraniol and linalol-are important components of flower perfumes which would be within the usual experience of the honeybees; the carboxylic acids, benzyl acetate and methyl benzoate, are less common constituents of flower perfumes, and the ketone methyl heptenone occurs only rarely and in small quantities in plant extracts.

The starred results in table 1 were obtained in experiments which were carried out in a heated greenhouse in October, when conditions were too cold for further work out-of-doors. The experiments with methyl heptenone indicated that the still air of the greenhouse was no more favourable than the open air to threshold perception. Variation in threshold sensitivity between individual bees, and variations due to temperature changes, were looked for but not observed, and so are not likely to have been of considerable extent.

The absolute values recorded under these experimental conditions convey little meaning in themselves, but the results indicate that the honeybees were not especially sensitive to those kinds of scent which occur in flower perfumes. 
Table 1. Threshold of scent perception. Various chemicals DILUTED WITH ETHYLENE GLYCOL

\begin{tabular}{|c|c|c|c|c|c|c|c|}
\hline \multirow[b]{2}{*}{ scent } & \multirow{2}{*}{$\begin{array}{l}\text { days of } \\
\text { training }\end{array}$} & \multicolumn{2}{|c|}{ significant positive series } & \multicolumn{2}{|c|}{ doubtful results } & \multicolumn{2}{|c|}{ negative series } \\
\hline & & $10^{6}$ dilution & landings & $10^{6}$ dilution & landings & $10^{6}$ dilution & landings \\
\hline geraniol & $1-2$ & $1: 33$ & $5+0-$ & - & - & $1: 100$ & $3+$ \\
\hline & $2-3$ & $1: 33$ & $6+1-$ & $1: 50$ & $6+2-$ & & \\
\hline linalol & $1-2$ & $1: 5$ & $9+3-$ & - & - & $1: 10$ & $0+$ \\
\hline phenyl ethyl alcohol & $1-2$ & $1: 33$ & $7+0-$ & $1: 100$ & $5+4-$ & $1: 10$ & $3+$ \\
\hline & $3-4$ & $1: 100$ & $7+0-$ & $1: 150$ & $11+7-$ & & \\
\hline benzyl acetate & $1-2^{*}$ & $1: 100$ & $8+3-$ & & & & \\
\hline & $3-4^{*}$ & - & - & - & - & $1: 300$ & $2+$ \\
\hline & $4-5^{*}$ & $1: 100$ & $10+1-$ & & & & \\
\hline & $1-2$ & $1: 100$ & $8+1-$ & - & - & $1: 500$ & $3+$ \\
\hline methyl benzoate & $4^{*}$ & $1: 25$ & $9+3-$ & $1: 100$ & $14+12-$ & & \\
\hline & $4 \frac{1}{2} *$ & $1: 100$ & $8+0-$ & - & - & $1: 300$ & $3+7-$ \\
\hline & $5^{*}$ & - & - & - & - & $1: 300$ & $6+12-$ \\
\hline methyl heptenone & $1-2$ & $1: 40$ & $9+2-$ & - & - & $1: 100$ & $6+11-$ \\
\hline & $1-2 *$ & $1: 40$ & $8+1-$ & - & - & $\begin{array}{l}1: 100 \\
1: 100\end{array}$ & $\begin{array}{l}1+8- \\
1+6-\end{array}$ \\
\hline
\end{tabular}

* Starred results refer to experiments conducted in a greenhouse, October 1952. The other experiments were conducted in the open air, June to September 1952.

\section{The scent of red-currant flowers}

Red currant (Ribes rubrum L.) and bilberry (Vaccinium myrtillus L.) are inconspicuous flowers which are rich in nectar and much visited by honeybees. However, Frisch (I9I9) concluded that these flowers were unscented both to honeybees and to humans.

Bilberry flowers were not available for experiment, but six bees were tested after $1 \mathrm{~h}$ of training to red-currant flowers.* Three successive tests, each with a fresh set of tubes, showed that the scent of the flowers was recognized $(8+1-$, $6+0-, 7+0-)$.

\section{DisCRIMINATION EXPERIMENTS}

In the threshold experiments trained bees were reluctant to alight on unscented tubes, but in discrimination experiments all the tubes contained attractive scents and the correct mixture was only a little more attractive than the others. This situation increased the experimental difficulties; training took appreciably longer and the bees sometimes showed discrimination at the beginning of a test but did not continue to do so as the test progressed.

\section{Discrimination between different mixtures of two scents}

Bees were trained to visit a mixture of equal parts of $1 \%$ solutions of two scents, and not to visit mixtures which contained a different proportion of the same two solutions.

Bees trained to equal parts of linalol and benzyl acetate learned during the third day to choose this mixture in preference to a mixture of 9 parts linolol/11 parts

* The red-currant flowers in the netted tube were covered with a layer of elm seeds, which were of the same colour. The other two netted tubes contained elm seeds only. 
benzyl acetate $(13+1-)$, but they did not distinguish it from a mixture of 19 parts linalol/21 parts benzyl acetate $(1+7-)$. In three further tests the $1: 1$ mixture was preferred at first to the 9:11 mixture, thus:

$$
\begin{array}{r}
8+3-\text { followed immediately by } 13+11-, \\
10+4-\text { followed immediately by } 7+8-, \\
5+1-\text { followed immediately by } 9+14-,
\end{array}
$$

Bees trained to equal parts of geraniol and phenyl ethyl alcohol, in a heated greenhouse, learned to choose this mixture in preference to a 9:11 mixture during their third day $(6+0-)$, but they did not distinguish it from a 19:21 mixture on that day $(14+13-)$ or the following one $(1+8-)$. On the fifth day the $1: 1$ mixture was again preferred to the $9: 11$ mixture $(7+2-)$.

\section{Recognition of adulteration of the attractive scent}

Bees were trained to visit $1 \%$ benzyl acetate and not to visit a mixture of 19 parts $1 \%$ benzyl acetate and 1 part $1 \%$ linalol. After 4 days the bees distinguished the training scent from a mixture containing 119 parts benzyl acetate and 1 part linalol $(32+20-)$ but failed to distinguish it from a 159:1 mixture $(9+7-$, followed by $6+13-$ ). This failure was followed by two failures with 119:1 mixture $(5+16-$ and $7+13-)$, but on the following day retrained bees distinguished it from a 79:1 mixture $(13+5-)$ and then from a 119:1 mixture $(13+8-)$. This was followed by failure to distinguish it from the 159:1 mixture $(11+16-)$ and successful recognition from the 119:1 mixture $(29+18-)$.

In a companion experiment on 21 July 1952 bees were trained to visit $1 \%$ phenyl ethyl alcohol and not to visit a mixture of 19 parts $1 \%$ phenyl ethyl alcohol and 1 part $1 \%$ geraniol. On the second day they distinguished the training scent from a 79:1 mixture $(15+2-)$ but not from a 159:1 mixture $(8+17-)$. Later that day they distinguished it from a $119: 1$ mixture $(8+2-)$ and from a 159:1 mixture $(41+23-)$. Sometimes the alighting of the bees was markedly affected by weather conditions (in ways which were not understood); on this day they landed on the tubes frequently and eagerly. On the following day, when they were reluctant to do so, the attempt to repeat the last result was not successful $(4+5-)$, but the bees did distinguish the training scent from the 119: 1 mixture $(10+1-)$.

\section{Recognition of a small quantity of scent, mixed with a large volume of another scent}

The following experiments were the converse of those recorded in the preceding section.

Bees were trained to visit a $1 \%$ mixture of benzyl acetate and linalol, and not to visit $1 \%$ benzyl acetate.*

On the fourth day they preferred a mixture which contained 1 part linalol in 179 parts benzyl acetate $(9+4-)$, on the fifth day they were trained to $1: 239$

* In this experiment the proportion of linalol in the training scent was gradually decreased, but in the companion experiment the proportion of geraniol remained at $1: 19$ throughout training. Alteration of the proportion did not produce more sensitive results, and it made training more difficult. 
$(12+5-$, followed by $14+8-)$ and then $1: 359(12+5-)$. On the sixth day they preferred $1: 359(7+0-)$, but tests on that day and the following one produced a neutral result $(11+9-)$ with respect to $1: 499$. Negative results $(3+10-$, followed by $16+22-$ ) were obtained at 1:499 concentration on the next day.

In the companion experiment bees were trained to visit a $1 \%$ mixture of 19 parts $1 \%$ phenyl ethyl alcohol and 1 part $1 \%$ geraniol, and not to visit $1 \%$ phenyl ethyl alcohol. On the third day they recognized a $1: 239$ mixture $(6+0-)$, and then a $1: 359$ mixture $(7+1-)$, but several tests with $1: 499$ mixture were not successful because the bees refused to alight $(2+3-$ only).

\section{Recognition of the adulteration of a mixture of scents}

Bees were trained to visit a $5 \%$ scent mixture, containing equal parts of benzyl acetate, citronellol, linalol, methyl benzoate and phenyl ethyl acetate, and not to visit an adulteration of this mixture with $0.5 \%$ geraniol. They distinguished the mixture from an adulteration with $0 \cdot 2 \%$ geraniol $(12+2-, 9+2-$, and $18+7-$ on three different tests), but not from adulteration with $0 \cdot 1 \%$ geraniol $(5+16-$ and $8+16-)$.

In the companion experiment geraniol was substituted for phenyl ethyl alcohol in the mixture, which was adulterated with the latter scent; the mixture was also distinguished from one adulterated with $0 \cdot 2 \%$ phenyl ethyl alcohol $(9+4-)$.

\section{COMPaRison BETWEen HUMANS AND HONEYBEES}

The absolute values for honeybee scent perception become more informative if they can be compared with the values for humans. This comparison was made in respect of the threshold values for two scents, methyl heptenone and geraniol.

Human scent perception varies considerably with circumstances and training; the present experiments were conducted with selected individuals-heavy smokers, those with colds, and others whose perception was deficient having been rejected after a preliminary trial. For those who were tested the following procedure was adopted.

One $2 \times \frac{3}{4}$ in. specimen tube was half-filled with the chosen scent in each of the following dilutions in ethylene glycol,

$$
\begin{aligned}
& 1: 1 \times 10^{4}-1: 3 \frac{1}{3} \times 10^{4}-1: 1 \times 10^{5}-1: 3 \frac{1}{3} \times 10^{5}- \\
& 1: 1 \times 10^{6}-1: 3 \frac{1}{3} \times 10^{6}-1: 10 \times 10^{6}-1: 33 \frac{1}{3} \times 10^{6}-1: 100 \times 10^{6} ;
\end{aligned}
$$

nine more tubes were filled with ethylene glycol only. The eighteen tubes were lettered at random, and randomly arranged on a bench. The person to be tested smelled one tube with $1 \%$ scent solution and another which contained ethylene glycol only, and he or she was then asked to pick up the eighteen lettered tubes, in any order, and to say which ones contained the scent. Any doubtfully scented tube could be put aside and subsequently re-examined.

For each series of experiments ten different people were tested; the same individuals were often used in several series. There were two series in respect of methyl heptenone and six series in respect of geraniol. 
I am indebted to Mr M. J. R. Healy for the analysis of the results. From them he concluded that the most sensitive $25 \%$ of the people who were tested could just recognize heptenone in $1: 1 \times 10^{6}$ dilution $\left(5 \%\right.$ fiducial limits, $1: 25 \times 10^{6}$ and $1: 435000)$. They could just recognize geraniol in $1: 333333$ dilution ( $5 \%$ fiducial limits, $1: 833333$ and $1: 175000)$.

These results indicate that the honeybee thresholds for perception of methyl heptenone and geraniol were about one-fortieth and one-hundredth, respectively, of the thresholds for humans.

There was less apparent difference between honeybees and humans in respect of the recognition of scent adulteration; two out of eight humans distinguished with certainty between $1 \%$ benzyl acetate and a mixture of 319 parts $1 \%$ benzyl acetate and 1 part $1 \%$ linalol, but they could not distinguish the 639:1 mixture. This experiment was open to the technical objection that the human nose had become adapted to benzyl acetate, so that only the adulterant was being perceived.

In another experiment, not open to this objection, eight tubes were filled with a mixture of equal parts of benzyl acetate and linalol, and seven other tubes were filled with the following mixtures: benzyl acetate alone, and mixed with linalol in the proportions $9: 1,4: 1,3: 1,2: 1,3: 2,11: 9$. There were thirty tests: Mr Healy's analysis showed that in about $61 \%$ the subjects guessed at random, and that half of the remaining $39 \%$ could just detect the difference between a $4: 1$ and a $1: 1$ mixture.

\section{THRESHOLD OF SCENT PERCEPTION IN ANTENNAE-OPERATED BEES}

Frisch (I92I) found that scent-trained bees would not respond after amputation of the eight terminal segments of both antennae, but that they responded when eight segments were cut off from one antenna and seven from the other; this result was confirmed by Frings (1944).

On 21 July 1953 six individually marked bees were trained to associate benzyl acetate with food, and they responded to this scent in $1: 100 \times 10^{6}$ dilution $(8+1-)$. Both antennae were then cut off at the seventh segment. When the bees recovered and returned to the apparatus their recognition of the scent was tested. On the day of operation they recognized the scent in $1: 300000$ dilution $(8+2-)$ but not in $1: 1 \times 10^{6}(11+18-)$. On the following day, in a combination of five tests, a neutral result was obtained in respect of the $1: 1 \times 10^{6}$ dilution $(25+27-)$.

This result suggests that a quantitative relationship may exist between the number of intact antennal sense organs and the threshold of scent perception.

\section{The ATtractiveness AND PERCePtion OF BEe SCENT}

Bees can expose a scent organ on their abdomen, and they use this scent as an instrument of communication (Sladen $190 \mathrm{I}-2$ ); foragers at dishes of syrup often open their scent organ in order to attract other bees (Frisch 1923), and the attractive odour may persist on a dish for at least $2 \mathrm{~h}$ (Kalmus \& Ribbands 1952).

Jacobs (I924) reported that single gland cells, of the same structure as the 500 to 600 which are concentrated together in the scent organ, occur on all parts of 
the body surface of the bee, and experimental results indicate that the odour of bees is recognizable by other bees even when their scent organs are not exposed (Ribbands 1954; Kalmus 1954). An experiment was therefore designed to determine whether a bee which alighted upon a tube without exposing its scent organ might be attracted to return to that tube by the odour which it left on it.

Three tubes filled with sugar solution were placed separately on the wheel, and one marked bee was trained to collect from any of them. Three tubes filled with water were then substituted, and the visits of the bee to each were recorded. Dilute sugar solution was used for training purposes, and the scent organ of the bee was not exposed, but it quickly learned to distinguish between the syrupfilled tubes and their water-filled substitutes, and it would seldom touch the latter. This occurred even when the sugar solution was made from Analar sucrose, yet repeated tests $(2+7-, 1+6-, 10+17-, 0+6-)$ showed that the bee

\section{Table 2. The attraction of its OWN SCent in the Choice} OF EMPTY TUBES BY ONE MARKED BEE

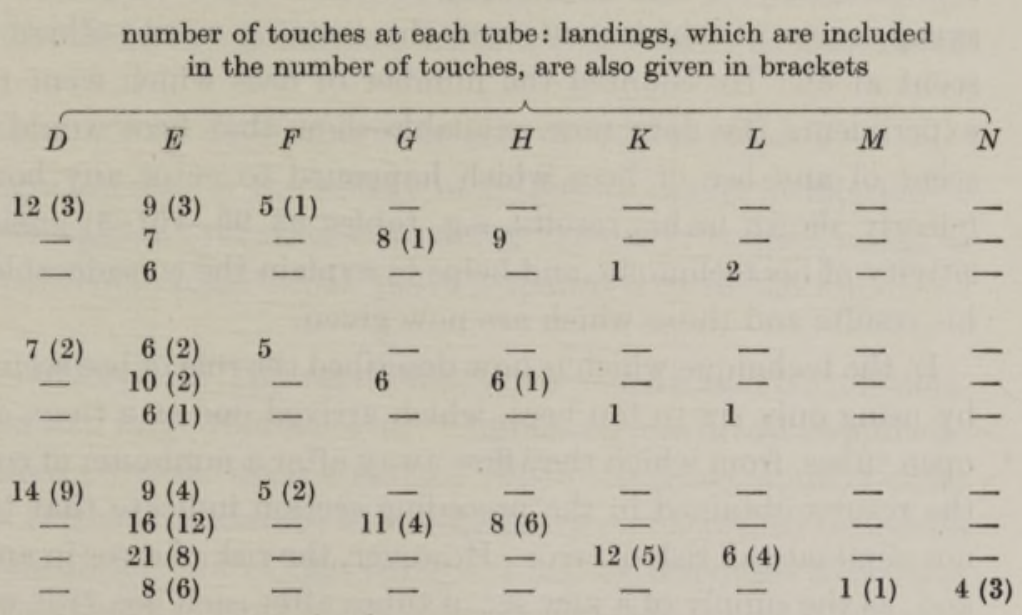

four trials $15.35-15.52 \mathrm{~h}$

four trials $16.02-16.23 \mathrm{~h}$

three trials $16.30-16.42 \mathrm{~h}$

6 June 1953

three trials $10.18-10.34 \mathrm{~h}$

three trials $10.45-11.07 \mathrm{~h}$

three trials 11.14-11.45 h

23 July 1953

four trials $14.30-15.00 \mathrm{~h}$

four trials $15.18-15.41 \mathrm{~h}$

four trials $15.52-16.27 \mathrm{~h}$

two trials $16.40-16.52 \mathrm{~h}$

did not distinguish between Analar sucrose solution and water until it touched them. To circumvent this difficulty (which demonstrated that the bee was guided by its own scent) no tube of sugar solution was used for more than one visit; the bee then touched or landed at the water without hesitation. The water-filled tubes were put out for 1 to $3 \mathrm{~min}$ at a time, and in order to preserve the training they were then replaced by sugar solution for 3 to $5 \mathrm{~min}$. Each time the bee touched a water-filled tube, however momentarily, that touch was recorded.* After several trials with three tubes, $D, E$ and $F$, two similar but unused tubes, $G$ and $H$, were substituted for $D$ and $F$; still later, substitutes $K$ and $L$ were provided for $G$ and $H$, and so on. The attraction of the visited tube $E$ was then found to be

* In the preceding experiments netted tubes eliminated the possibility of any use of 'contact odour'; in this experiment all definite touches with the antennae were recorded as such, but the bee often inspected the tubes by flying round them in a very close circle, and the observer could not be infallible in such circumstances. Honeybees can certainly recognize minute concentrations of bee scent from a distance (Kalmus \& Ribbands 1952), but in colony defence recognition is often aided by contact odour (Ribbands 1954). 
significantly greater than that of the unvisited tubes. The results are given in table 2. It is likely that bee scent was only deposited on the tube in appreciable quantities on occasions when the bee alighted on it. In table 2 touches include these landings, and the number of landings is shown in brackets after the number of touches.

In another experiment preference for the touched tube developed very quickly. One bee, presented with three unused water-filled tubes, landed immediately on one of them and then repeatedly returned to it. In six trials between 14.30 and $15.42 \mathrm{~h}$ touches (landings in brackets) at the three tubes, $A, B$ and $C$, were in succession, $0-5(5)-0, \quad 0-2(2)-1(1), \quad 0-2(1)-1(1), \quad 0-3(3)-1, \quad 1-1(1)-1, \quad 0-2(2)-0$ respectively.

\section{TECHNICAL PROBLEMS IN THE STUDY OF SCENT PERCEPTION}

The scent of the honeybees themselves is a serious obstacle to a study of their scent perception. Having trained large groups of bees to collect sugar syrup from a small scented box, Frisch (I9I9) offered them a choice of similar boxes, without syrup, some of which contained the training scent, others another scent or no scent at all. He counted the number of bees which went to each box; in such experiments the data now available show that bees would be attracted by the scent of any bee or bees which happened to enter any box; this disadvantage (clearly shown in his results, e.g. tables 93-99, 101-3) greatly reduced the sensitivity of his technique, and helps to explain the considerable differences between his results and those which are now given.

In the technique which is now described the role of bee scent was greatly reduced by using only six to ten bees, which arrived one at a time, and by offering them open tubes, from which they flew away after a minimum of contact. Nevertheless, the results obtained in the preceding section indicate that these precautions did not eliminate all risk of error. However, the risk of error in any one test was small, and, as the supply of a new set of tubes after each bee visit would have been very laborious, repetition of the tests was chosen as an alternative precaution. Because of the amount of repetition, and the consistency of the results in different but related experiments, I consider that the effect of bee scent has not vitiated the present series of threshold and discrimination experiments.

The threshold values for scent perception might ideally be measured in terms of the quantity of scent contained in some standard volume of air, but the olfactory acuity of the honeybee has not been examined in this way. Instead, various scents have been mixed with a solvent, and the threshold has been expressed in terms of the minimum dilution of the solvent to which the bees will respond. The present experiments follow the example of Frisch (1919) in using human scent perception as a yardstick; this comparison helps us to appreciate the results, but its disadvantages are important. In several respects there is no exact parallel between experiments with bees and with humans. Humans sniff the tubes and draw in a current of air from the surface of the scented liquid, but bees cannot do this. Humans tell us what they can smell; without training, but the honeybees are trained to the scents over a period. 
Moreover, the experiments with honeybees depend upon the limitations of the training technique. The threshold values for honeybee scent perception can probably be accurately determined by the technique now described, because a trained bee has an incentive to go to the training scent whenever it can perceive it. The training technique is less satisfactory for determinations of discrimination between mixtures of scents, because a trained bee has some incentive to go to a mixture which is similar to, but not the same as, that to which it has been trained. The results from complementary discrimination experiments illustrate this difficulty - bees trained to $1 \%$ benzyl acetate only distinguished between this scent and a 119:1 mixture of benzyl acetate and linalol, but bees trained to a mixture of these two scents distinguished 359:1 mixture from $1 \%$ benzyl acetate; similar results were obtained with phenyl ethyl alcohol and geraniol; the first of these experiments certainly did not reveal the extent of the bees' capacity for discrimination, and the second may have suffered to a lesser extent from the same disadvantage.

Perhaps a training technique which used punishments as well as rewards would reveal much greater discrimination than that which has now been demonstrated.

\section{THE OLFACTORY ACUITY OF HONEYBEES AND OF OTHER INSECTS}

Most of the striking examples of the ability of insects to orient in relation to odours which are imperceptible to man involve either the use of contact odour or the recognition of a particular scent which plays a special part in the life of the species concerned.

Non-contact odours involve the appreciation of a very small number of molecules of scent dispersed in a large volume of air. Contact odours involve appreciation of a layer of scented particles upon a surface; when the sense organ touches that surface it at once comes into contact with very many more scented molecules than are in the air immediately above that surface; thus, by responses to contact odours, an insect might appear to have a very superior olfactory acuity although, in the absence of any contact, its achievement would not be outstanding. The odour trails of ants (Forel 1910) and the ability of the hymenopterous egg parasite Trichogramma evanescens to detect an odour imparted to host eggs by other females which have walked over them (Salt 1937) are two examples of the use of contact odour.

The second category of response, which seems to involve a very superior olfactory acuity, is displayed by those Lepidoptera in which one sex is attracted upwind through a long distance by a specific scent given off by its mate (Mayer I900; Fabre I9I I; Rau \& Rau I929). Fabre's male moths were not confused in the presence of other strong odours; this suggests that their odour receptors might be especially sensitive to the particular scent, and hence the possibility that some insects possess a mechanism through which they are hypersensitive to one compound, which might be some specific component in their own metabolism; if this surmise were correct their olfactory acuity might be in other respects unremarkable; such a mechanism would have great survival value, both for mating and for food and host finding. 
This surmise would resolve the dilemma outlined in the introduction to this paper, concerning the apparent contradiction between the honeybee's extreme sensitivity to its own body scent and the evidence which suggested that its threshold for the perception of ordinary scents was similar to that of man. Moreover, the olfactory acuity of man for various substances appears to surpass that of the parasitic wasp Habrobracon juglandis (Wirth 1928), the beetle Geotrupes sylvaticus (Warnke I93I) and the fly Musca domestica (Wieting \& Hoskins 1939); these results, obtained with diverse materials and very different insects, all conform with Frisch's conclusion concerning the honeybee.

However, the results now presented show that the olfactory acuity of the honeybee in respect of the scents used is of a superior order to that of man, and the establishment of that fact makes the suggestion of specialized hypersensitivity less necessary in relation to the honeybee. Moreover, there is an important difference between the honeybee's sensitivity to bee scent and the sensitivity of Lepidoptera to mating scents; the latter are perhaps hypersensitive to one substance only, whereas the honeybee can discriminate between its own odour and the odour of honeybees from other colonies-this attribute implies that any hypersensitivity would be to a range of compounds, and such a mechanism is more difficult to imagine than hypersensitivity to a particular one.

\section{Conclusions}

The most surprising and important result was obtained in the experiment in which it was shown that a bee was attracted to the body scent which it left behind some time previously on a glass tube (not a good surface for scent retention) on which it landed momentarily without exposing its scent gland. One may suppose that a substantially greater quantity of bee scent would be left behind by a bee which actually foraged from such a source, or which trampled over a flower, and therefore that this bee scent will often aid bees in their foraging. Body scent might not serve only as an attraction; from many kinds of flower a visiting bee removes all the available nectar or pollen, and the supply is not replenished for some time - bees foraging from such flowers might save time by learning to avoid blossoms impregnated with bee scent (Frisch 1919, showed that bees could be trained either to avoid scents or to go to them).

There are a number of conclusions which conflict with those of Frisch (1919), the differences being attributable to the more sensitive technique now used. The threshold of perception of honeybees is of a lower order than that of man, and they were easily trained to red-currant flowers, which were previously supposed to be inodorous to them. Moreover, they distinguished between a pure scent and a 359:1 mixture of that scent and another one - the comparable value obtained by Frisch was 24:1.

Antennal amputation indicated that the acuity of scent perception varies with the number of intact sense organs on the antennal segments.

For reasons mentioned previously the present technique is likely to underestimate, perhaps seriously, the extent to which honeybees can distinguish between 
mixtures of varying proportions of the same scents. Nevertheless, their discrimination of a small quantity of one scent in a large bulk of another one was similar to that of humans, despite the human advantage that the nose became insensitive to the scent which was present in bulk. When the experiments were so designed that the adaptation of the human nose could be ruled out the honeybee's discrimination-between 50:50 and 45:55 mixtures-was much better than that of humans. The recognition of hivemates by their scent (Kalmus \& Ribbands 1952) requires a highly developed ability to distinguish between mixtures of scents, which probably often differ only in the proportions of their ingredients.

Comparison between the discrimination experiments suggested that bees responded to the absence of one of the two scents to which they had been trained more readily than to the addition of the same scent when they had only been trained to the other scent.

In my view the discrimination experiments are of value, not so much for the conclusions reached, but rather because they reveal a path which is still to be explored. The comparison between the scent perception of bees and of other insects also emphasizes the problems which remain unsolved.

\section{REFERENCES}

Fabre, J. H. I91 I Social life in the insect world. London: Fisher Unwin. Forel, A. I910 Das Sinnesleben der Insekten. München: Reinhardt.

Frings, H. 1944 J. exp. Zool. 97, 123-34.

Frisch, K. von 1919 Zool. Jb. Abt. 3, 37, 1-238.

Frisch, K. von I921 Zool. Jb. Abt. 3, 38, 1-68.

Frisch, K. von 1923 Zool. Jb. Abt. 3, 40, 1-186.

Hertz, Mathilde I934 Z. vergl. Physiol. 21, 463-7.

Jacobs, W. 1924 Z. Morph. Oekol. Tiere, 3, 1-80.

Kalmus, H. \& Ribbands, C. R. 1952 Proc. Roy. Soc. B, 140, 50-9.

Kalmus, H. 1954 Brit. J. Anim. Behav. 2, 63-7.

Mayer, A. G. 1900 Psyche, 9, 15-20.

Rau, P. \& Rau, Nellie L. 1929 Trans. Acad. Sci. St Louis, 26, 81-221.

Ribbands, C. R. 1954 Proc. Roy. Soc. B, 142, 514-24.

Salt, G. 1937 Proc. Roy. Soc. B, 122, 57-75.

Sladen, F. W. L. I90 I Glean. Bee Cult. 29, 639-40.

Sladen, F. W. L. 1902 Ent. Mon. Mag. 38, 208-11.

Warnke, G. I931 Z. vergl. Physiol. 14, 121-99.

Wieting, J. O. G. \& Hoskins, W. M. 1939 J. Econ. Ent. 32, 24-9.

Wirth, W. ${ }^{9} 928$ Biol. $Z$ bl. 48, 567-76. 